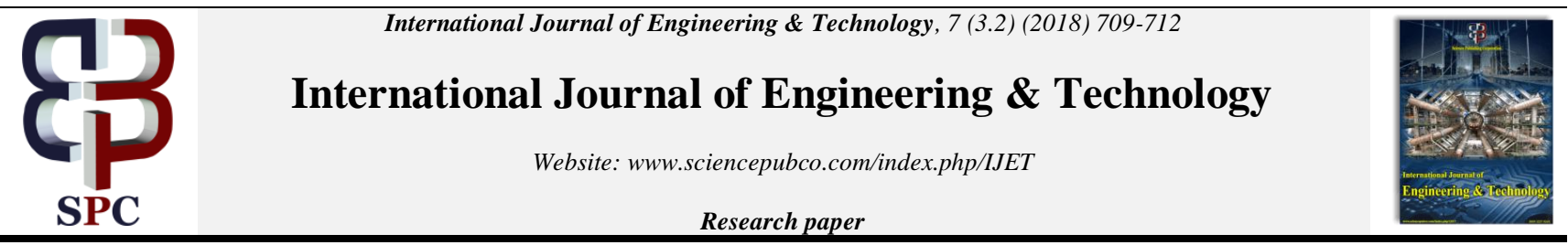

\title{
Impact Suboptimal Signal Degradation Handoff (SDH) Properties to Handoff Parameters
}

\author{
Maksum Pinem*, Leonardo Siregar, Fadilah Rahma, S Suherman \\ Electrical Engineering Department, Universitas Sumatera Utara, Medan, Indonesia \\ *Corresponding author E-mail: maksum@usu.ac.id
}

\begin{abstract}
Study on mobile handoff is aim at avoiding inefficient mobile station transfer from a base station to other base station. Efficient handoff leads to smooth communication and seamless mobile station migration. This paper studies impact of cost and window length properties of the suboptimal signal degradation handoff (SDH) to handoff performance parameters such as received signal level, delay and number of handoff. Simulation results show that cost and average length increment cause signal degradation and delay increment. However, number of handoff decreases. The suggested optimal cost (c) for average window length (dr) 0 and 10 are 0.65 and 0.25 . However, dr $=$ 20 and 30 experience poor signal for any cost values.
\end{abstract}

Keywords: Handoff, optimal cost, average window length

\section{Introduction}

Handoff is a channel migration mechanism from one cell to other cell following the mobile station movement. A more frequent handoff occurs in a smaller cell [1]. Frequent handoff burdens switching within cellular network: so that the frequency should be optimized by finding the optimal handoff parameters. Some handoff parameters that determine handoff performance are the suitable received signal level, the number of the occurred handoff, handoff failure and handoff delay [2]-[5]. Properties selection of a handoff algorithm is important to reduce radio transmission cost as well as to maintain quality of services (QoS) [6], [7].

Within a cellular network, the number of slots or channels, allocated frequencies, network codes are defined [1][8]. The coverage is also defined whether femto, pico, micro, macro or mega cell [9]. Signal within a cellular network is fluctuated, composed by direct signal, reflection, diffraction and scattering [6], [10], [11] which is affected by path loss and fading [6], [11]-[13]. In order to analyze the system, signal propagation within a cellular network is modelled either using continues time model or discrete time model [14]-[17]. Signal fluctuation is averaged in term of exponential average window so that the received signal smoother [16] [18][19].

Handoff between base stations are classified into: soft handoff (make before break) and hard handoff (break before make) [9]. Handoff decision is based on either centralized or decentralized decision: Network Controlled Handoff (NCHO), Mobile Assisted Handoff (MAHO) and Mobile Controlled Handoff (MCHO) [19], [20].

The handoff execution is based on signal level, traffic intensity, carrier to interference ratio, bit error rate, transmission power and mobile speed [21]. This paper discusses handoff initiation by using suboptimal Signal Degradation Handoff (SDH) [16] and its properties impact to handoff performance parameters

\section{System Model}

A homogeneous cellular network consists of three base stations (BTS): $\mathrm{BTS}_{1}, \mathrm{BTS}_{2}$, and $\mathrm{BTS}_{3}$ are modeled. Each bases station

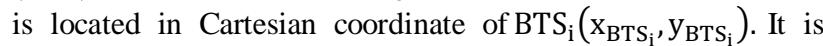
assumed that each BTS has hexagonal equivalent coverage which covered by omnidirectional antennas. Distance $d_{i, k}$ is the distance between the $\mathrm{k}^{\text {th }}$ mobile station sample to BTS .

$\mathrm{d}_{\mathrm{i}, \mathrm{k}}=\sqrt{\left(\mathrm{x}_{\mathrm{k}}-\mathrm{x}_{\mathrm{BTS}_{\mathrm{i}}}\right)^{2}+\left(\mathrm{y}_{\mathrm{k}}-\mathrm{y}_{\mathrm{BTS}}\right)^{2}}$

By assuming that number of mobile station within a cell is constant with random direction $\theta[0,2 \pi]$, then the mobile station coordinate is $\left(\mathrm{x}_{\mathrm{k}}, \mathrm{y}_{\mathrm{k}}\right)[22]$ :

$\mathrm{x}_{\mathrm{k}}=\mathrm{r} \cos \theta_{\mathrm{k}-1}+\mathrm{x}_{\mathrm{k}-1}$

$\mathrm{y}_{\mathrm{k}}=\mathrm{r} \sin \theta_{\mathrm{k}-1}+\mathrm{y}_{\mathrm{k}-1}$

Where $\mathrm{r}=\mathrm{d}_{\mathrm{s}}$ (sampel distance), $\mathrm{k} \geq 2$ (the $\mathrm{k}^{\text {th }}$ sample). 


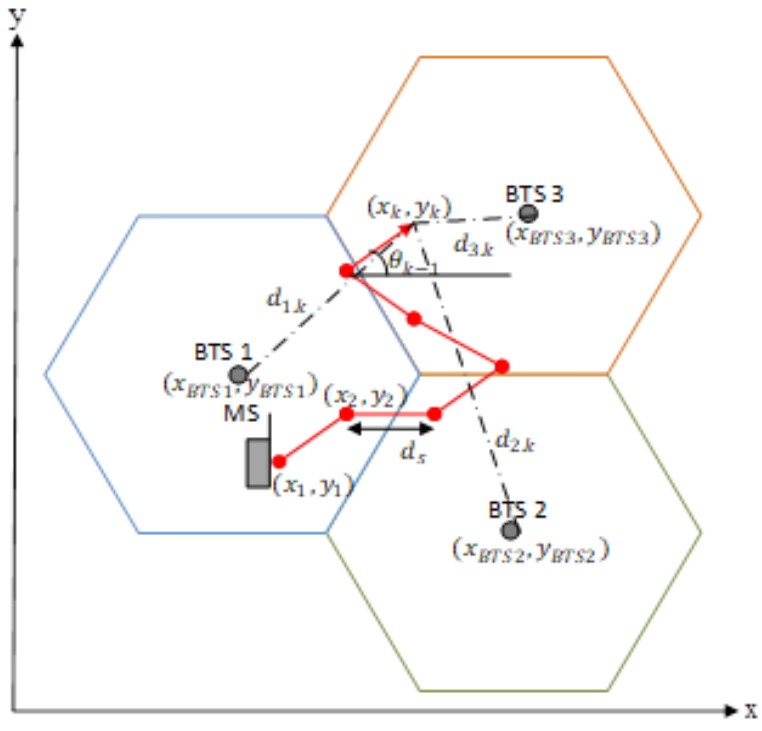

Fig.1: System model

The signal level accepted by a mobile station from BTS $_{\mathrm{i}}$ along path $d_{i, k}$ is approximated by [8], [23]:

$\mathrm{S}_{\mathrm{i}, \mathrm{k}}\left(\mathrm{d}_{\mathrm{i}, \mathrm{k}}\right)=\mathrm{K}_{1}-\mathrm{K}_{2} \log \left(\mathrm{d}_{\mathrm{i}, \mathrm{k}}\right)+\mathrm{W}_{\mathrm{i}, \mathrm{k}}$

where $i=1,2,3 . S_{i, k}$ be the signal level received by BTS $_{i}$ on sample-k. $d_{i, k}$ is distance $B T S_{i}$ to sample-k. $K_{1}$ : path loss constant. $\mathrm{K}_{2}$ : path loss exponent. $\mathrm{W}_{\mathrm{i}, \mathrm{k}}$ : Gaussian distribution for shadowing effect $\left(\mathrm{N}\left(0, \sigma_{\mathrm{i}}^{2}\right)\right)$.

$\mathrm{W}_{\mathrm{i}, \mathrm{k}}$ is represented by a zero-mean of autocorrelation function [24], [25]

$\mathrm{E}\left[\mathrm{W}_{\mathrm{i}, \mathrm{k}} \mathrm{W}_{\mathrm{i}, \mathrm{k}+\mathrm{m}}\right]=\sigma_{\mathrm{i}}{ }^{2} \mathrm{a}_{\mathrm{i}}{ }^{|\mathrm{m}|}$

$\mathrm{W}_{\mathrm{i}, \mathrm{k}}$ is recursively calculated from [25]:

$\mathrm{W}_{\mathrm{i}, 0}=\sigma_{\mathrm{i}}^{2} \mathrm{~N}_{\mathrm{i}, 0}$

$\mathrm{W}_{\mathrm{i}, \mathrm{k}+1}=\mathrm{a}_{\mathrm{i}} \mathrm{W}_{\mathrm{i}, \mathrm{k}}+\sigma_{\mathrm{i}} \sqrt{1-\mathrm{a}_{\mathrm{i}}^{2}} \mathrm{~N}_{\mathrm{i}, \mathrm{k}}$

where $\mathrm{N}_{\mathrm{i}, \mathrm{k}}(0,1)$ is a random variable. $\mathrm{d}_{\mathrm{i}}$ is a correlation distance. $\sigma_{i}^{2}$ is shadow fading. $a_{i}$ is correlation coefficient of $N_{i, k} ; a_{i}=$ $\exp \left(-\mathrm{vt}_{\mathrm{s}} / \mathrm{d}_{\mathrm{i}}\right)$.

\section{Simulation Model}

The received signal by mobile station is discretely sampled every $t_{k}=k t_{s}$ where $t_{s}$ is the sampling time period. Distance between sampling periods is $d_{s}=v_{s}$ assuming that speed $v(m / s)$ is constant. To minimized signal fluctuation, signal level is processed by using exponential average [15], [16]. The average signal level is expressed by:

$\bar{S}_{i, k}\left(d_{i, k}\right)=e^{-\left(\frac{d_{s}}{d_{r}}\right)} \bar{S}_{i, k-1}\left(d_{i, k-1}\right)+\left(1-e^{-\left(\frac{d_{s}}{d_{r}}\right)}\right) S_{i, k}\left(d_{i, k}\right)$

Suboptimal Signal Degradation Handoff

The suboptimal SDH determines handoff decision by using time limitation between $\mathrm{k}$ and $\mathrm{k}+1$, as a function of $\mathrm{Q}$ [16], [25]:

$\mathrm{U}_{\mathrm{k}}=\left\{\begin{array}{c}1, \text { jika } Q\left[\frac{\mathrm{S}^{\prime}\left(\mathrm{BTS}_{\text {canditate }}(\mathrm{k}), \mathrm{k}\right)}{\bar{\sigma}}\right]+\mathrm{c} \\ <Q\left[\frac{\mathrm{S}^{\prime}\left(\mathrm{BTS}_{\text {active }}(\mathrm{k}), \mathrm{k}\right)}{\bar{\sigma}}\right] \\ 0, \text { others }\end{array}\right.$

where,
$\mathrm{Q}(\mathrm{z}) \triangleq \frac{1}{\sqrt{2 \pi}} \int_{\mathrm{z}}^{\infty} \mathrm{e}^{-\mathrm{t}^{2} / 2} \mathrm{dt}$

$c(\operatorname{cost}):$ parameter trade-off varied based on cellular environment.

\section{A. Handoff Parameters}

\section{1) Call Quality Signal Level (CQSL)}

CQSL is the sum of sampling points of received signal with the unacceptable signal points, approximated as [6]:

$\operatorname{CQSL}(\mathrm{l}) \geq \frac{\sum_{\mathrm{k} \in \mathrm{N}_{\mathrm{g}}} A_{\mathrm{k}}}{\mathrm{N}}-\frac{\mathrm{S}_{\mathrm{min}}\left|\mathrm{N}_{\mathrm{g}}\right|\left(\mathrm{N}-\left|\mathrm{N}_{\mathrm{g}}\right|\right)}{\mathrm{pN}^{2}}$

Where, $\forall \mathrm{k} \in \mathrm{N}_{\mathrm{g}}$,

$A_{k}=\left\{\begin{array}{cc}S_{i, k} \text { jika } S_{i, k} \leq S_{\max } \\ S_{\max } \text { others }\end{array}\right.$

$\mathrm{N}_{\mathrm{g}}$ : the number of samples of the acceptable signal strength. $\mathrm{N}_{\mathrm{b}}$ : the number of sample of poor signal where: $\mathrm{S}_{\mathrm{i}, \mathrm{k}}<S_{\text {min }}$ with assuming $S_{\max }=1,5 S_{\min }$. $C:$ the value where signal is unacceptable. N: good and bad signal numbers, $N_{g}=\left\{k \mid S_{i, k} \geq S_{\min }\right\}$ and $\mathrm{N}_{\mathrm{b}}=\left(\mathrm{N}-\left|\mathrm{N}_{\mathrm{g}}\right|\right)$. p: maximum acceptable proportion of signal samples below $S_{\min }$.

The average CQSL(l) for s path of $\mathrm{l}=\left(\mathrm{l}_{1}, \mathrm{l}_{2}, \ldots, \mathrm{l}_{\mathrm{s}}\right)$ :

$\overline{\mathrm{CQSL}}=\sum_{\mathrm{l}=1}^{\mathrm{S}} \frac{\operatorname{CQSL}(\mathrm{l})}{\mathrm{s}}$

\section{2) Delay Handoff}

Delay is the time when mobile station is not served by the closest base station. Delay Mobile station position is in between two equivalents base stations [16]:

$\operatorname{Delay}(\mathrm{l})=\sum_{\mathrm{k}=1}^{\mathrm{N}} \mathrm{D}_{\mathrm{k}}$

where, $D_{k}=\left\{t_{s}\right.$, if there is a delay

The average delay can be written as:

$\overline{\text { Delay }}=\frac{1}{\mathrm{~s}} \sum_{\mathrm{l}=1}^{\mathrm{s}}$ Delay $(\mathrm{l})$

3) Number of Handoff

When handoff occurs, decision variable $U_{k}=1$, the opposite condition is no handoff exists $U_{k}=0$. The number of handoff $\left(\mathrm{U}_{\mathrm{k}}(\mathrm{l})\right)$ at path $\mathrm{l}$ is expressed by:

$\mathrm{U}_{\mathrm{k}}(\mathrm{l})=\sum_{\mathrm{k}=1}^{\mathrm{N}-1} \mathrm{U}_{\mathrm{k}}$

The average number of handoff is:

$\overline{\text { Handoff }}=\sum_{\mathrm{l}=1}^{\mathrm{s}} \frac{\mathrm{U}_{\mathrm{k}}(\mathrm{l})}{\mathrm{s}}$

\section{Simulation Results}

By using Matlab simulation[26], [27] and the aforementioned model are evaluated. The BTS distance is set to be $100 \sqrt{3} \mathrm{~m}$. The BTS coordinates are $\mathrm{BTS}_{1}(100,161.6), \mathrm{BTS}_{2}(250,75)$, $\mathrm{BTS}_{3}(250,248.2)$. It is assumed that mobile station moves straight every $1 \mathrm{~m}$ from $\operatorname{MS}(200,0)$ with angle $\theta$.

The number of path $\mathrm{s}=500$, each path has $\mathrm{N}=400$ signal samples, with distance of $d_{s}=1 \mathrm{~m}$

Next, it is assumed that the signal level along the path is $\mathrm{S}_{\mathrm{i}, \mathrm{k}}\left(\mathrm{d}_{\mathrm{i}, \mathrm{k}}\right)=\mathrm{K}_{1}-\mathrm{K}_{2} \log \left(\mathrm{d}_{\mathrm{i}, \mathrm{k}}\right)+\mathrm{W}_{\mathrm{i}, \mathrm{k}}$ where $\mathrm{K}_{1}=85 \mathrm{~dB} \quad$; $\mathrm{K}_{2}=35 \mathrm{~dB}$; speed $\mathrm{v}=2 \mathrm{~m} / \mathrm{s}$, sample period is $\mathrm{t}_{\mathrm{s}}=0.5 \mathrm{~s}$ and 
deviation standard $\sigma=5 \mathrm{~dB}, \mathrm{~S}_{\min }=$ and $\mathrm{S}_{\max }=1,5 \mathrm{~S}_{\min }$, proportional $\mathrm{p}=0$.

The call scenario is using retry model, the drop state occurs after signal level is 12 times under $S_{\min }$ (with drop timer $6 \mathrm{~s}$ ).

Figure 2 shows impact cost variation $(\mathrm{c}=0.025,0.04,0.06,0.1$, $0.13,0.25,0.35,0.45,0.55,0.65)$ and average window length $\left(\mathrm{d}_{\mathrm{r}}\right.$ $=0,10,20,30)$ to handoff parameters.

In Fig. 2a, cost (c) increment causes the value of signal strength $\overline{\mathrm{CQSL}}$ decreases. Initially, signal decreases exponentially up to $c=0.5$, then linearly to $c=1$. Signal strength decreases when dr increases.

In Fig.2b., cost (c) and $d_{r}$ increments result delay increasing. Its increment is opposite to signal strength. The lower the dr: the lower the delay.

In Fig. 2c, Handoff number decreases significantly when cost increases. The higher the dr: the lower the number of handoff.

The optimal properties are approximated by considering $\overline{\mathrm{CQSL}}$ close to $S_{\min }=15 \mathrm{~dB}$, and $\overline{\text { Delay }}$ closes to $40 \mathrm{~s}$ and handoff number minimized. Figure 3 shows the trade-off between handoff properties to handoff performances: $\overline{\mathrm{CQSL}}, \overline{\mathrm{Handoff}}$ and $\overline{\text { Delay. }}$

The optimal value is obtained by setting cost (c) at $d_{r}=0$, where the first suggestion is $c=0.65$. For $d_{r}=10$, it is suggested that $c$ $=0.25$. And for $d_{r}=20$ and 30 , should be avoided as signal is poor.
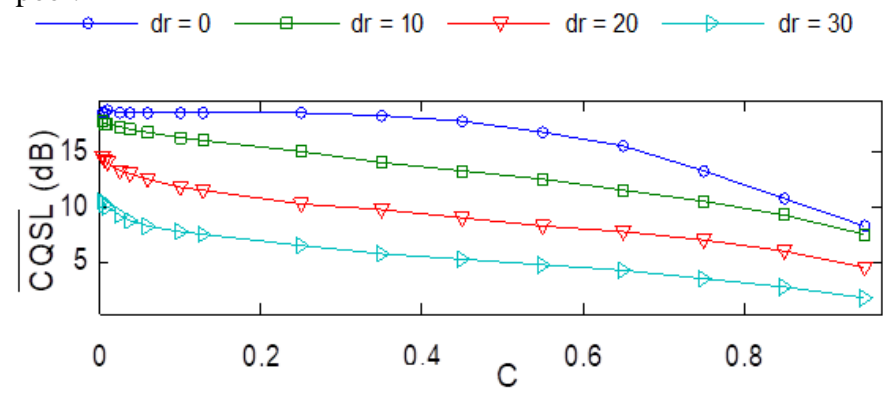

(a)
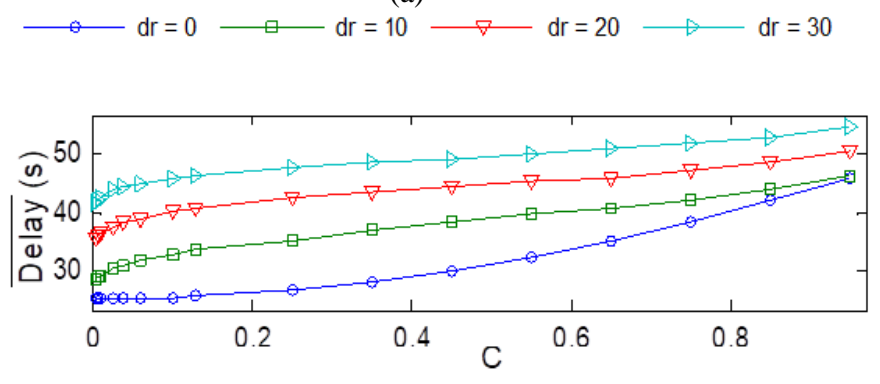

(b)


(c)

Fig.2: Cost Variation to handoff performance

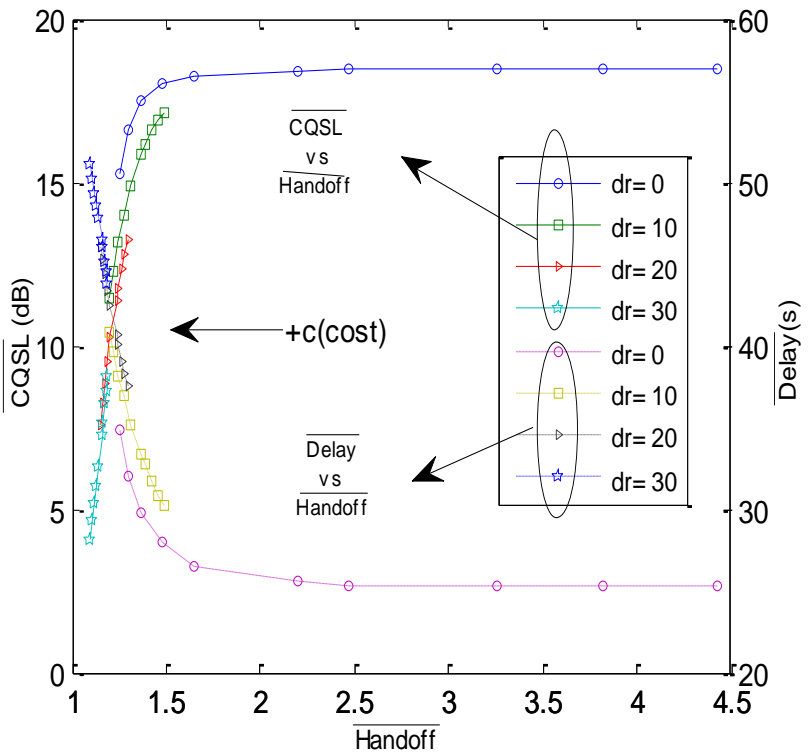

Fig. 3: Handoff trade-off parameter of the suboptimal SDH

\section{Conclusion}

This paper has examined the impacts of properties suboptimal SDH to handoff performance parameters. From the simulation results and analysis, the variations of parameter cost (c) average window length $\left(\mathrm{d}_{\mathrm{r}}\right)$ have relation to signal quality, delay and handoff frequency.

Cost (c) increment causes $\overline{\mathrm{CQSL}}$ decreases. Signal strength decreases when $d r$ increases. Cost (c) and $d_{r}$ increments result delay increasing. Handoff frequency decreases significantly when cost increases.

The optimal $\overline{\mathrm{CQSL}}$ is closed to $\mathrm{S}_{\mathrm{min}}$ and $\overline{\text { Delay }}$ closes to $40 \mathrm{~s}$ and handoff number is minimum for $c>0.5$. Values $d_{r}=20$ and 30 should be avoided.

\section{Acknowledgement}

This research was funded by Research Institute of North $\mathrm{Su}$ matera University with TALENTA of North Sumatera University with Research Contract of Fiscal Year 2017, Number: 5338 / UN5.1.R / PPM / 2017 dated May 22, 2017.

\section{References}

[1] M. Gudmundson, "Analysis of Handoff Algorithms," IEEE, pp. 537-542, 1991.

[2] O. K. V. Veeravalli, "A Locally Optimal Handoff Algorithms for Cellular Communication," IEEE Trans. Veh. Technol., vol. 46, no. 3, pp. 603-609, 1997.

[3] S. C. P. Marichamy, "On Threshold Setting and Hysteresis Issues of Handoff Algorithms," in Proc. IEEE Personal Wireless Communication Conf., 1999, pp. 436-440.

[4] S. M. P. Marichamy, S. Chakrabarti, "Overview of Handoff Schemes in Cellular Mobile Networks and Their Comparative Performance Evaluation," IEEE Veh. Technol., pp. 1486-1490, 1999.

[5] A. F. S. Moghaddam, V. Tabataba, "New Handoff Initiation Algorithm (Optimum Combination of Hysteresis and Threshold Based Methods)," in EEE Veh. Technol. Conf., 2000, p. 15671574.

[6] M. Z. MN. Halgamuge, HL. Vu, "Evaluation of Handoff Algorithms Using a Call Quality Measure with Signal Based Penalties," in IEEE Commun. Society, 2006, pp. 30-35.

[7] D. Subramaniam et al., "A Stacked Planar Antenna with Switchable Small Grid Pixel Structure for Directive High Beam Steering Broadside Radiation," Int. J. Eng. Technol., vol. 7, no. 2.5, pp. 122-127, Mar. 2018.

[8] H. V. D. Tripathi, JH. Reed, "Handoff in Cellular System," EEE Commun., pp. 26-36, 1998. 
[9] M. N. Halgamuge, "Performance Evaluation and Enhancement of Mobile and Sensor Networks," in -, 2006.

[10] T. S. Rappaport, Wireless Communication: Principles and Pratice, 2nd ed. New Jersey: Prentice Hall, 2002.

[11] H. Suherman, Mubarakah, N., Sagala, R.S., Prayitno, "Wififriendly building, enabling wifi signal indoor: An initial study," IOP Conf. Ser. Earth Environ. Sci., vol. 126, no. 1, p. 012022 , 2018.

[12] P. D. MZ. Mahmood, "Shadow Fading in Mobile Radio Channel",", pp. 291-295.

[13] A. Goldsmith, Wireless Communi-cation, vol. Cambridge. 2005.

[14] B. L. Leu, A. E., Mark, “A Discrete-Time Approach to Analyze Hard Handoff Performance in Cellular Networks," IEEE Trans. Wirel. Commun, vol. 3, no. 5, pp. 1721-1733, 2004.

[15] A. E. Tang, S., Mark, B. L., Leu, An Exact Solution For Outage Probability in Cellular Network. George Mason University.

[16] U. Akar, M., Mitra, "Variations on Optimal and Suboptimal Handoff Control for Wireless Communication Systems," IEEE J. Sel. Areas Commun, vol. 19, pp. 1173-1185, 2001.

[17] R. Rahim, T. Afriliansyah, H. Winata, D. Nofriansyah, Ratnadewi, and S. Aryza, "Research of Face Recognition with Fisher Linear Discriminant," IOP Conf. Ser. Mater. Sci. Eng., vol 300, p. 012037, 2018.

[18] and H. S. Zhou, Yan, George Cherian, "Access terminal adaptation of handover parameter," 9,949, 2017.

[19] G. L. Stüber, Principles of mobile communication, 3rd ed. Springer, 2017.

[20] V. Asadi, A., Wang, Q., \& Mancuso, "A survey on device-todevice communication in cellular networks," IEEE Commun. Surv. Tutorials, vol. 16, no. 4, pp. 1801-1819, 2014.

[21] N. Pahal, S., \& Rathee, "ANALYSIS OF HYSTERESIS MARGIN FOR EFFECTIVE HANDOVER IN 4G WIRELESS NETWORKS," ICTACT J. Commun. Technol., vol. 7, no. 4, 2016.

[22] Y. Ardian, "ANALISIS JENIS MATERIAL TERHADAP JUMLAH KUAT SINYAL WIRELESS LAN MENGGUNAKAN METODE COST-231 MULTIWALL INDOOR," Matrix J. Manaj. Teknol. dan Inform., vol. 7, no. 3, pp. 68-73, 2017.

[23] M. Halgamuge, "Performance Evaluation and Enhancement of Mobile and Sensor Networks," University of Melbourne, 2006.

[24] M. Gudmundson, "Electronics Letter," Correl. Model Shad. Fading Mob. Radio Syst., vol. 27, no. 23, pp. 2145-2146, 1991.

[25] M. Alsamhi, S. H., Ansari, M., Hebah, M., Ahmed, A., Hatem, A., \& Alasali, "Adaptive Handoff Prediction and Appreciate Decision Using ANFIS between Terrestrial Communication and HAP."

[26] T. Listyorini and R. Rahim, "A prototype fire detection implemented using the Internet of Things and fuzzy logic," World Trans. Eng. Technol. Educ., vol. 16, no. 1, pp. 42-46, 2018.

[27] P. harliana and R. Rahim, "Comparative Analysis of Membership Function on Mamdani Fuzzy Inference System for Decision Making," J. Phys. Conf. Ser., vol. 930, no. 1, p. 012029, Dec. 2017. 